\title{
Influence of supply voltage and frequency variations on the electrical equipment and power consumption in $\mathrm{LV}$ and MV distribution networks
}

\section{Illia Diahovchenko ${ }^{1}$,}

Nataliia Sushchenko,

Anton Shulumei²,

Oleksandr Strokin ${ }^{3}$

${ }^{1}$ Electrical Power Engineering Department, Sumy State University,

2 Rymskogo-Korsakova St., 40007 Sumy, Ukraine

Email: ilya.dyagovchenko@gmail.com

${ }^{2}$ Technical Thermophysics Department, Sumy State University,

2 Rymskogo-Korsakova St., 40007 Sumy, Ukraine

${ }^{3}$ Department of Applied Hydro- and Aeromechanics,

Sumy State University,

2 Rymskogo-Korsakova St., 40007 Sumy, Ukraine
This paper is focused on the analysis of supply voltage and frequency quality in low voltage and medium voltage distribution power systems. The influence of supply voltage and frequency variations, within the limits defined in the valid standards, on the power network's parameters has been evaluated using the stochastic theory and the statistical analysis methods. The circuit of RLC-load was considered for numerical evaluation. The probability distribution of supply voltage and frequency was defined and the suggestions on optimum voltage and frequency quality parameters regarding electric energy consumption, power losses and electrical equipment lifespan were given.

Keywords: voltage variation, frequency variation, power quality, electric energy meter, normal distribution, Pearson's chi-squared test, power distribution system

\section{INTRODUCTION}

The power system's management should be aimed at maintaining such work parameters that the required reliability and power quality (PQ) are ensured. This means that one should not, although it is technically possible, strive to maintain absolute reliability and PQ, 'driving' the parameters of the power system mode into the required framework, since it is not cost-ef- fective. Though, it is crucial that PQ is constantly maintained at the proper level.

The principles of power system's operation and control are based on certain power quality requirements, which are formulated in domestic and international standards. For most standardized PQ indicators normally acceptable and maximum permissible values are established. Herewith, the values should not go beyond the maximum permissible values and should be 
within the range of normally acceptable values with 0.95 probability, while the measurement time interval is not less than $24 \mathrm{~h}$. These requirements must be respected in all normal, repair and post-emergency conditions, except for those caused by natural disasters and unforeseen circumstances (e.g. hurricane, earthquake, flood, fire, etc.).

Power quality is characterized by the voltage quality and the frequency quality of the alternating current $(\mathrm{AC})$ voltage. The voltage quality is evaluated by several indicators, most of which are characterized by acceptable values. Among others, the following important parameters are listed and defined in the EN 50160-2010:

- nominal voltage,

- frequency of the supply voltage,

- long interruption of the supply voltage,

- short interruption of the supply voltage,

- rapid voltage change,

- voltage dip,

- voltage fluctuation,

- voltage swell,

- voltage unbalance,

- voltage variation,

- flicker severity,

- harmonic voltage.

EN 50160 gives the main voltage parameters and their permissible deviation ranges at the customer's point of common coupling in public low voltage (LV), medium voltage (MV) and high voltage (HV) power systems, under normal operating conditions.

One of the most important PQ indicators is the root mean square (RMS) value of the voltage magnitude variation at a given point in the network, which is understood as slow smooth deviations from the nominal or desired value that occur continuously over time. Quantitatively, the voltage variations are estimated by the value of the steady-state voltage deviation

$$
\begin{aligned}
& \Delta U=U-U_{\text {rated }}, \\
& \delta U=\frac{U-U_{\text {rated }}}{U_{\text {rated }}} 100 \%,
\end{aligned}
$$

where $U_{\text {rated }}$ is the rated operating voltage and $U$ is the actual voltage value.
Power systems' voltage stability depends on the relationships between the load bus voltage magnitude, the reactive power injection or absorption and the power supplied to the load [1]. Thus, voltage variations are mainly due to load pattern, changes of load or nonlinear loads, and, as a result, changes of the voltage drop in the network's elements. Another reason for the voltage deviations is a change in the voltage profile in the power centers, i.e. on the buses of power plants or secondary voltage buses of step-down substations, where distribution power systems are connected [2].

Earlier in Ukraine, the state standard GOST 13109-07 was in force, where the normally acceptable and maximum permissible values of voltage magnitude variation were set as $\delta U_{n o r m}= \pm 5 \%$ and $\delta U_{\max }= \pm 10 \%$, respectively. Since 2014, power quality in Ukrainian LV and MV power networks has been standardized in accordance with EN 50160-2010, which is being used in the countries of the European Union (EU). EN 50160-2010 indicates that the range of variation of the root mean square (rms) magnitude of supply voltage is $\pm 10 \%$ for $95 \%$ of the 10-minute mean RMS values over each oneweek period.

The frequency of supply voltage is the frequency of fundamental harmonic voltage, measured as the mean value during a given time interval. In Ukraine and in the EU, the rated frequency is $50 \mathrm{~Hz}$. To assess the quality of the frequency the parameter of frequency deviation is used, which is understood as slow smooth changes of frequency (less than 1\% per second) relative to its nominal value

$$
\delta f=\frac{f-f_{\text {rated }}}{f_{\text {rated }}} 100 \%,
$$

where $f_{\text {rated }}$ is the rated frequency and $f$ is the actual frequency value.

The reason for frequency deviation is the imbalance of the generated and consumed active power in the electric power system. The former state standard GOST 13109-07 sets the normally acceptable and maximum permissible values of frequency variation as $\delta f_{\text {norm }}= \pm 0.2 \mathrm{~Hz}$ and $\delta f_{\max }= \pm 0.4 \mathrm{~Hz}$, respectively. As specified in EN 50160-2010, the network frequency has to be 
- for interconnected supply systems: $50 \mathrm{~Hz} \pm 1 \%$ (49.5-50.5 Hz) for $95 \%$ and $50 \mathrm{~Hz}-6 \% \ldots+4 \%$ (47$52 \mathrm{~Hz}$ ) for $100 \%$ of a week;

- for non-interconnected supply systems: $50 \mathrm{~Hz} \pm 2 \%$ for $95 \%$ and $50 \mathrm{~Hz} \pm 15 \%$ for $100 \%$ of a week.

For networks operating in an islanded condition the frequency is allowed to vary within a wider range.

The requirements of EN 50160-2010 regarding voltage and frequency deviations are less strict, compared to those of GOST 1310997. It should be noted that EN 50160 is principally informative and accepts no responsibility when the limits are exceeded. On the other hand, the consumers' point of view is usually totally different - they regard the limits given in EN 50160 as requirements that must be guaranteed by the supplier. However, for some consumers even fulfilling the requirements given in EN 50160 does not assure a satisfactory level of PQ. In such cases, the level of PQ required must be defined in a separate agreement between a utility and a consumer.

The objective of this study is to estimate the current situation about supply voltage and frequency quality and to evaluate how their deviations within the thresholds defined in the valid standards affect the parameters of an electric network (e.g. power and currents at the consumer's side, load power factor), by means of the stochastic theory and the statistical analysis methods. On the other hand, this study aims to define the probability distribution of supply voltage and frequency, and to find the optimum voltage quality parameters regarding power consumption and losses.

\section{CAUSES OF VOLTAGE AND FREQUENCY VARIATIONS AND THE WAYS TO MAINTAIN VOLTAGE AND FREQUENCY STABILITY}

\section{Undesired impacts of voltage variations and voltage control strategies}

Supply voltage quality is a complex term concerning voltage deviations from its ideal characteristics. A practical approach for the analysis of supply voltage quality parameters by means of stochastic theory is discussed in [3]. The main problem for consumers is often supposed to be too low voltage in the feeder. As the network's impedance varies slightly, the voltage variation is mainly due to load current variations. Therefore, the voltage on the transformer's secondary side is often stepped up to ensure the rated voltage level during peak loads [3]. The other issue influencing PQ is the rising penetration level of distributed generation (DG) in LV distribution networks. The paper [4] attempts to quantify the possible negative impacts on the voltage profile of different deployment levels of DG in secondary networked distribution systems. The authors determined the critical amount of distributed energy resources (DERs) that the LV networks can withstand without exhibiting undervoltage and overvoltage problems or unexpected load tripping. DG can provide voltage support, maintaining its appropriate value at the end of the feeder. However, the voltage may exceed the upper standardized limit in the points of DG injections. The paper [5] assesses the impact of high photovoltaic $(\mathrm{PV})$ penetration on voltage profiles in residential neighbourhoods. The simulation results show that the PV penetration level does not adversely influence the voltage profile of a typical distribution grid when the DERs capacity does not exceed $2.5 \mathrm{~kW}$ per household on average [5]. However, power generation by PV-panels and their connection to the network through current converters can negatively affect PQ [6]. The resonance phenomenon in the LV networks with a high number of distributed power inverters for PV-panels and the recommendations to improve the PQ characteristics of the inverters are discussed in [7].

Voltage variations affect the operation of both power consumers and the electrical network. For example, the rotation speed of the rotor of an asynchronous motor changes with voltage deviations. If the voltage on the stator's winding drops by $15 \%$, then the torque on the shaft will decrease by $1 / 4$, and the asynchronous motor will most likely stop or, if it comes to starting, will not start at all. With a reduced supply voltage, the current consumption increases, the stator's windings heat up more, and the service life of the motor will be greatly reduced. If the motor constantly operates at a supply voltage of $90 \%$ of the rated value, then its service life will be reduced by half. If the supply 
voltage exceeds the rated value by $1 \%$, then the reactive power consumption of a motor will increase by about $5 \%$, and the overall efficiency of such a motor will decrease.

Negative voltage deviations cause decrease in illumination, which may influence the labour productivity in enterprises that require eye strain. With an increase in voltage magnitude by $10 \%$, the service time of incandescent lamps decreases 4 times, and with a voltage decrease by $10 \%$, the light flux of an incandescent lamp decreases by $40 \%$, while the flux of fluorescent lamps decreases by $15 \%$. If the voltage turns out to be $90 \%$ of the rated value when the fluorescent lamp is turned on, then it will flicker, and at $80 \%$ it will not start at all. Voltage variations affect power losses in transformers and power lines [2].

Also some loads may drop off by themselves without any action of protective relays when voltage is unsustainable. Table 1 summarizes the examples of interruption voltages due to distribution protection [8].

Table 1. Voltage variation tolerances for load-and-control equipment

\begin{tabular}{cc}
\hline Device & Voltage deviation \\
\hline Communication equipment & $\pm 5 \%$ \\
\hline $\begin{array}{c}\text { Computers, data processing } \\
\text { equipment }\end{array}$ & $\pm 10 \%$ \\
\hline Contactors, motor starts & $-15 \% \ldots+10 \%$ \\
\hline Illumination & $-10 \%,-25 \%$ \\
- Fluorescent & $+18 \%$ \\
\hline Incandescent & $\pm 10 \%$ \\
\hline Induction motors & variable \\
\hline
\end{tabular}

There are two ways to meet the requirements of EN 50160 regarding the voltage magnitude variations. The first is to reduce power losses, the second is to regulate the voltage. The voltage drop in the electrical distribution network can be defined as

$$
\Delta U=\frac{P \cdot R+Q \cdot X}{U_{s c(\text { subst })}},
$$

where $P$ and $Q$ are the active and the reactive power transmitted through the line, respective- ly, $R$ and $X$ are resistance and the reactance of the line, respectively, and $U_{s c(s u b s t)}$ is the voltage at the power supply center or at the transformer substation.

Ways to reduce power losses are the following:

- $R$ optimization: the cross-section of the line conductors should be chosen in accordance with the minimum possible loss conditions. The economic feasibility of using a conductor with a larger cross-sectional area should be proven vs having larger power losses but with a thinner (and cheaper) line conductor.

- $X$ optimization: longitudinal compensation of line reactance which, however, enhances the danger of high short-circuit currents if $X \rightarrow 0$.

- $Q$ reduction: installation of static VAr compensators to reduce reactive power transmission through the distribution power system. The desired effect can be achieved by means of capacitor banks or synchronous motors operating under over-excitation. Additionally, compensation of $Q$ allows one to reduce power losses and save electric energy, since the overall power losses will decrease.

- Adequate choice of power transformers for the expected power flow (i.e. satisfying an optimal transformer load factor).

Transformers in the supply center regulate the voltage $U_{s c}$. They are equipped with automatic devices for adjusting the transformation coefficient in accordance with the current loading. Regulation under load is possible in a range of $\pm 16 \ldots 20 \%$ of the rated voltage. Transformers at intermediate substations $U_{\text {subst }}$ can perform voltage regulation as well. The windings of these transformers are equipped with switchable taps, which are designed for the $\pm 5 \%$ control range with a step of $2.5 \%$. Switching is made without excitation when the transformer is disconnected from the grid.

$R$ and $X$ are to be chosen at the designing stage of the power network, and further operational change of these parameters is impossible. $Q$ and $U_{\text {subst }}$ can be adjusted during network loading seasonal changes, but it is necessary to manage the operating modes of reactive power compensation centrally, in accordance with the current operating mode of the network as a whole, which is the responsibility of an electric 
energy supplying utility. As for the voltage regulation $U_{s c}$ from the power center, this is the most convenient way for the supplying utility, which allows one to adjust voltage properly, according to the load schedule of the networks.

Under operating conditions, it is not possible to constantly monitor voltage deviations at each electric device. Therefore, in the power transmission and distribution systems the so-called control points are set, where voltage tolerance thresholds are assessed. If the voltage in these most characteristic points is within acceptable limits, then it does not go beyond the acceptable limits for the most consumers as well. Test points are usually selected on the secondary voltage buses at the main load nodes, as well as on the buses of power plants.

\section{Influence of frequency variation on the electrical equipment}

Frequency variation directly affects the operation of power consumers. For instance, the frequency deviations worsen the operation of electric motors, causing changes in their rotation frequency, active and reactive power consumption. The highest danger of frequency deviation is for the equipment of power plants. The performance of mechanisms that overcome the static pressure (e.g. feed pumps for the power plant's auxiliaries, which overcome the high pressure from the boiler) is reduced [2]. In addition, the reduced frequency in the power network affects the service life of steel-containing equipment (e.g. electric motors, transformers), due to an increase in the magnetization current and additional heating of steel elements. However, frequency variation has an insignificant effect on the operation of furnaces and lighting loads.

For the power system the dependences of active $P$ and reactive $Q$ power on frequency is shown in Fig. 1 [2].

The dependencies in Fig. 1 are static frequency load characteristics. When system frequency decreases due to the active power generation deficiency, consumers reduce their load, trying to maintain frequency at the appropriate level. As can be seen from Fig. 1, the frequency decrease to $f_{1}$ leads to an increase in the reactive power $Q$ consumed by the load, which entails a de-

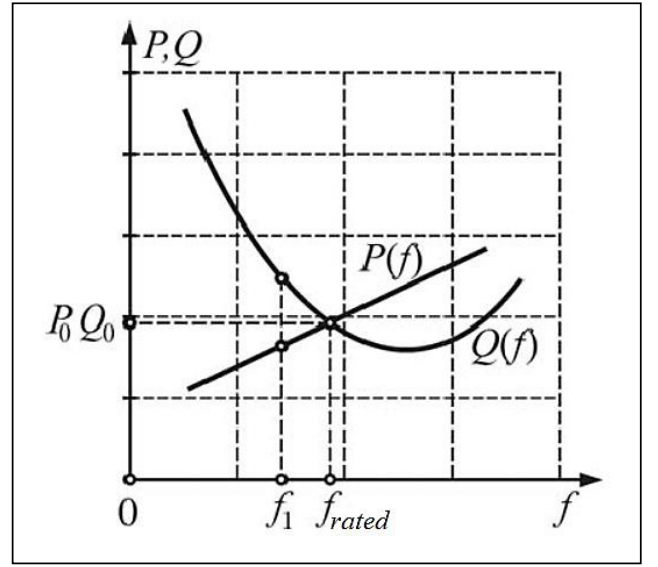

Fig. 1. Static frequency load characteristics

crease in voltage at the point of load connection. In this case, the active power $P$ consumption is reduced. Typically, the increase in reactive power consumption is higher than the decrease in active power, which leads to an increase in total power flows over the network elements and, consequently, to higher power and energy losses.

At any time in the power system a balance of active power is maintained:

$$
\sum P_{G}=\sum P_{L}-\Sigma \Delta P
$$

Here $\Sigma P_{G}$ is the total power of generators at power plants, $\Sigma P_{L}$ is the total power consumption of the power system, including in-house loads of power plants, and $\Sigma \Delta P$ is the total power losses in electrical networks.

At any frequency the power generated by power plants is equal to power consumption. At the same time, the nominal value of frequency in the power system indicates that the generated power is sufficient to cover the normal needs of consumers. A lower than rated frequency indicates a shortage of generated power, and a higher frequency indicates an excess of power in the system.

To control the frequency, the turbines of generators are equipped with speed controllers. At the event of a power shortage and a sharp frequency decrease as a result of primary and secondary regulation, all power plants will become fully loaded. If the power of generators disconnected during an accident is greater than the reserve at all power plants of the system, then the frequency will not be restored to 
its rated value. During the event of a significant power shortage the frequency decrease will be high. To prevent an avalanche of frequency, automatic quick-action measures must be taken. Frequency recovery is carried out by automatic frequency unloading, at which some consumers are disconnected [2]. Deliberate curtailment of some consumers allows one to save generating capacities in operation, to provide power supply for the rest of the loads.
TESTING THE HYPOTHESIS ABOUT

THE DISTRIBUTION LAW OF

THE RANDOM VARIABLES OF VOLTAGE

AND FREQUENCY

According to the data provided by the local electricity distributor for the feeder, which supplies household loads (single-story residential buildings) in a rural area, the results of voltage (Table 2) and frequency (Table 3) measurements were

Table 2.0 bservations of random voltage value

\begin{tabular}{|c|c|c|c|c|c|c|c|}
\hline \multirow[b]{2}{*}{ No. } & \multirow{2}{*}{$\begin{array}{c}\text { Deviation, } \\
\pm \%\end{array}$} & \multicolumn{3}{|c|}{ Overvoltage deviations regarding $U_{\text {rat }}$} & \multicolumn{3}{|c|}{ Undervoltage deviations regarding $\boldsymbol{U}_{\text {rat }}$} \\
\hline & & $\begin{array}{l}\text { Number of } \\
\text { results, } n\end{array}$ & $U / U_{\text {rat }}$ & $\begin{array}{l}\text { U random } \\
\text { value, } \mathbf{V}\end{array}$ & $\begin{array}{l}\text { Number of } \\
\text { results, } n\end{array}$ & $U / U_{\text {rat }}$ & $\begin{array}{l}U \text { random } \\
\text { value, } \mathbf{V}\end{array}$ \\
\hline 1 & 0 & 264 & 1 & 220 & 191 & 0.995 & 218.9 \\
\hline 2 & 0.5 & 201 & 1.005 & 221.1 & 179 & 0.99 & 217.8 \\
\hline 3 & 1 & 181 & 1.01 & 222.2 & 176 & 0.985 & 216.7 \\
\hline 4 & 1.5 & 158 & 1.015 & 223.3 & 174 & 0.98 & 215.6 \\
\hline 5 & 2 & 154 & 1.02 & 224.4 & 162 & 0.975 & 214.5 \\
\hline 6 & 2.5 & 152 & 1.025 & 225.5 & 150 & 0.97 & 213.4 \\
\hline 7 & 3 & 150 & 1.03 & 226.6 & 144 & 0.965 & 212.3 \\
\hline 8 & 3.5 & 144 & 1.035 & 227.7 & 140 & 0.96 & 211.2 \\
\hline 9 & 4 & 140 & 1.04 & 228.8 & 132 & 0.955 & 210.1 \\
\hline 10 & 4.5 & 134 & 1.045 & 229.9 & 118 & 0.95 & 209 \\
\hline 11 & 5 & 118 & 1.05 & 231 & 94 & 0.945 & 207.9 \\
\hline 12 & 5.5 & 92 & 1.055 & 232.1 & 76 & 0.94 & 206.8 \\
\hline 13 & 6 & 72 & 1.06 & 233.2 & 64 & 0.935 & 205.7 \\
\hline 14 & 6.5 & 62 & 1.065 & 234.3 & 50 & 0.93 & 204.6 \\
\hline 15 & 7 & 48 & 1.07 & 235.4 & 38 & 0.925 & 203.5 \\
\hline 16 & 7.5 & 45 & 1.075 & 236.5 & 24 & 0.92 & 202.4 \\
\hline 17 & 8 & 39 & 1.08 & 237.6 & 16 & 0.915 & 201.3 \\
\hline 18 & 8.5 & 23 & 1.085 & 238.7 & 22 & 0.91 & 200.2 \\
\hline 19 & 9 & 12 & 1.09 & 239.8 & 15 & 0.905 & 199.1 \\
\hline 20 & 9.5 & 10 & 1.095 & 240.9 & 15 & 0.9 & 198 \\
\hline 21 & 10 & 10 & 1.1 & 242 & 8 & 0.895 & 196.9 \\
\hline 22 & 10.5 & 8 & 1.105 & 243.1 & 6 & 0.89 & 195.8 \\
\hline 23 & 11 & 7 & 1.11 & 244.2 & 6 & 0.885 & 194.7 \\
\hline 24 & 11.5 & 6 & 1.115 & 245.3 & 6 & 0.88 & 193.6 \\
\hline 25 & 12 & 6 & 1.12 & 246.4 & 6 & 0.875 & 192.5 \\
\hline 26 & 12.5 & 3 & 1.125 & 247.5 & 3 & 0.87 & 191.4 \\
\hline 27 & 13 & 1 & 1.13 & 248.6 & 3 & 0.865 & 190.3 \\
\hline 28 & 13.5 & 1 & 1.135 & 249.7 & 2 & 0.86 & 189.2 \\
\hline 29 & 14 & 1 & 1.14 & 250.8 & 1 & 0.855 & 188.1 \\
\hline 30 & 14.5 & 1 & 1.145 & 251.9 & 1 & 0.85 & 187 \\
\hline 31 & 15 & 1 & 1.15 & 253 & - & - & - \\
\hline
\end{tabular}


compiled.The results are shown for phase A. Measurements were taken at the feeder endpoint, i.e. for the last consumer on the line. A total of 4266 measurements were made for the voltage value and 1987 measurements for the frequency value. The measurements were taken at 1 min step.

According to the data from Table 2, the dependence of $f(U)$, Fig. 2, was built.

According to the data from Table 3, the dependence of $f(f)$, Fig. 3 , is built.
Estimating the shape of the voltage and frequency bar charts, it was hypothesized that the dependences $f(U)$ and $f(f)$ obey the normal (Gaussian) distribution, and the probability density function of the variable under study coincides with the Gaussian function [9]

$$
f(x)=\frac{1}{\sigma_{x} \sqrt{2 \pi}} \cdot e^{-\frac{\left(x_{i}-m_{x}\right)^{2}}{2 \cdot \sigma_{x}^{2}}},
$$

Table 3. Observations of random frequency value

\begin{tabular}{|c|c|c|c|c|c|c|c|}
\hline \multirow[b]{2}{*}{ No. } & \multirow{2}{*}{$\begin{array}{c}\text { Deviation, } \\
\pm \%\end{array}$} & \multicolumn{3}{|c|}{ Overvoltage deviations regarding $f_{\text {rat }}$} & \multicolumn{3}{|c|}{ Undervoltage deviations regarding $\boldsymbol{f}_{\text {rat }}$} \\
\hline & & $\begin{array}{l}\text { Number of } \\
\text { results, } n\end{array}$ & $f / f_{\text {rat }}$ & $\begin{array}{l}f \text { random } \\
\text { value, } \mathrm{Hz}\end{array}$ & $\begin{array}{l}\text { Number of } \\
\text { results, } n\end{array}$ & $f / f_{\text {rat }}$ & $\begin{array}{c}\text { frandom va- } \\
\text { lue, } \mathrm{Hz}\end{array}$ \\
\hline 1 & 0 & 142 & 1 & 50 & 99 & 0.9996 & 49.98 \\
\hline 2 & 0.04 & 70 & 1.0004 & 50.02 & 98 & 0.9992 & 49.96 \\
\hline 3 & 0.08 & 68 & 1.0008 & 50.04 & 87 & 0.9988 & 49.94 \\
\hline 4 & 0.12 & 67 & 1.0012 & 50.06 & 76 & 0.9984 & 49.92 \\
\hline 5 & 0.16 & 66 & 1.0016 & 50.08 & 65 & 0.998 & 49.9 \\
\hline 6 & 0.2 & 66 & 1.002 & 50.1 & 66 & 0.9976 & 49.88 \\
\hline 7 & 0.24 & 64 & 1.0024 & 50.12 & 64 & 0.9972 & 49.86 \\
\hline 8 & 0.28 & 63 & 1.0028 & 50.14 & 62 & 0.9968 & 49.84 \\
\hline 9 & 0.32 & 62 & 1.0032 & 50.16 & 60 & 0.9964 & 49.82 \\
\hline 10 & 0.36 & 60 & 1.0036 & 50.18 & 55 & 0.996 & 49.8 \\
\hline 11 & 0.4 & 56 & 1.004 & 50.2 & 52 & 0.9956 & 49.78 \\
\hline 12 & 0.44 & 45 & 1.0044 & 50.22 & 44 & 0.9952 & 49.76 \\
\hline 13 & 0.48 & 26 & 1.0048 & 50.24 & 38 & 0.9948 & 49.74 \\
\hline 14 & 0.52 & 22 & 1.0052 & 50.26 & 34 & 0.9944 & 49.72 \\
\hline 15 & 0.56 & 20 & 1.0056 & 50.28 & 24 & 0.994 & 49.7 \\
\hline 16 & 0.6 & 18 & 1.006 & 50.3 & 18 & 0.9936 & 49.68 \\
\hline 17 & 0.64 & 16 & 1.0064 & 50.32 & 11 & 0.9932 & 49.66 \\
\hline 18 & 0.68 & 11 & 1.0068 & 50.34 & 8 & 0.9928 & 49.64 \\
\hline 19 & 0.72 & 9 & 1.0072 & 50.36 & 6 & 0.9924 & 49.62 \\
\hline 20 & 0.76 & 6 & 1.0076 & 50.38 & 6 & 0.992 & 49.6 \\
\hline 21 & 0.8 & 6 & 1.008 & 50.4 & 7 & 0.9916 & 49.58 \\
\hline 22 & 0.84 & 4 & 1.0084 & 50.42 & 4 & 0.9912 & 49.56 \\
\hline 23 & 0.88 & 4 & 1.0088 & 50.44 & 4 & 0.9908 & 49.54 \\
\hline 24 & 0.92 & 4 & 1.0092 & 50.46 & 3 & 0.9904 & 49.52 \\
\hline 25 & 0.96 & 3 & 1.0096 & 50.48 & 2 & 0.99 & 49.5 \\
\hline 26 & 1 & 2 & 1.01 & 50.5 & 3 & 0.9896 & 49.48 \\
\hline 27 & 1.04 & 2 & 1.0104 & 50.52 & 3 & 0.9892 & 49.46 \\
\hline 28 & 1.08 & 1 & 1.0108 & 50.54 & 0 & 0.9888 & 49.44 \\
\hline 29 & 1.12 & 1 & 1.0112 & 50.56 & 1 & 0.9884 & 49.42 \\
\hline 30 & 1.16 & 1 & 1.0116 & 50.58 & 1 & 0.988 & 49.4 \\
\hline 31 & 1.2 & 1 & 1.012 & 50.6 & - & - & - \\
\hline
\end{tabular}


where $m_{x}$ is the mean or expectation of the distribution (and also its median and mode), $\sigma_{x}$ is the standard deviation, and $x_{i}$ is the random value of the investigated variable.

If the values of voltage and frequency obey the Gaussian distribution, the results of the experiments should be processed using the following numerical characteristics of the random variables and their systems [9]:

1. Mean or expectation (the mean probability of a random variable)

$$
M[x]=m_{x}=\int_{-\infty}^{\infty} x f(x) d x .
$$

Mathematical assessment of the mean of expectation

$$
M^{*}[X]=m^{*}{ }_{x}=\frac{1}{n} \sum_{i=1}^{n} x_{i},
$$

where $n$ is the number of tests taken (sample's volume).

2. Variance of a random variable (a measure of the variation of a given random variable, i.e. its deviation from the mathematical expectation)

$$
D[x]=D_{x}=\int_{-\infty}^{\infty}\left(x-m_{x}\right)^{2} f(x) d x .
$$

Mathematical assessment of the variance

$$
D^{*}[X]=D_{x}^{*}=\frac{1}{n-1} \sum_{i=1}^{n}\left(x_{i}-m_{x}^{*}\right)^{2},
$$

or

$$
D^{*}[X]=D^{*}{ }_{x}=\frac{1}{n-1}\left(\sum_{i=1}^{n} x_{i}^{2}-\frac{\left(\sum_{i=1}^{n} x_{i}\right)^{2}}{n}\right)
$$

3. Standard deviation (the scatterplot of the values of a random variable relative to its median)

$$
\sigma_{x}=\sqrt{D_{x}}
$$

Mathematical assessment of the standard deviation

$$
\sigma_{x}^{*}=\sqrt{D_{x}^{*}}
$$

Voltage and frequency variations in the electrical network have a stochastic nature. Means of expectation for both values can be obtained from the data given in Tables 2 and 3, using the formulas (7) and (8). Get $m_{U}=220.526 \mathrm{~V}$ and $m_{f}=49.9998 \mathrm{~Hz}$.

The Pearson's chi-squared test [10] was employed to validate the hypothesis of a normal distribution of random voltage $U$ and frequency $f$. At $n=4266$, the voltage measurement results concentrated in the range $187 \mathrm{~V} \leq U_{\text {rated }} \leq 253 \mathrm{~V}$. This range was divided into 12 intervals of $5.5 \mathrm{~V}$ width, according to the Sturges' rule [11]

$$
l=1+[3.322 \cdot \lg n],
$$

where $l$ is the number of intervals.

The frequency measurement results were concentrated in the range $49.4 \mathrm{~Hz} \leq f_{\text {rated }} \leq 50.6 \mathrm{~Hz}$. According to (14), this range was divided into 12 intervals of $0.1 \mathrm{~Hz}$ width.

The experimental value of the chosen criterion can be found by

$$
\chi_{\exp }^{2}=\sum_{i=1}^{l} \frac{\left(\gamma_{i}-n p_{i}\right)^{2}}{n p_{i}},
$$

where $\gamma_{i}$ is the empirically obtained investigated value, $p_{i}$ is the probability of a random variable $X$ falling into the $i$-th interval, and $h$ is the width of a single interval.

Assuming the significance level $\alpha=0.05$ and the number of degrees of freedom $k_{U}=9$ for voltage and $k_{f}=9$ for frequency, the critical values of the Pearson's chi-squared test were determined: $\chi_{\operatorname{cr}(U)}^{2}=16.919$ and $\chi_{\operatorname{cr}(f)}^{2}=16.919$. Here the degree of freedom of the random value $x$ is defined as

$$
k_{x}=l-1-r,
$$

where $r$ is the number of parameters of a supposed distribution law (if a distribution law is expected to be normal, then the mean or expectation and the standard deviation are assessed, $r=2)$.

After the calculation, the experimental values of the Pearson's chi-squared test were obtained: $\chi_{\exp (U)}^{2}=16.058$ and $\chi_{\exp (f)}^{2}=16.581$. In both cases, the condition $\chi_{\exp (x)}^{2}<\chi_{\operatorname{cr}(x)}^{2}$ is satisfied, therefore, the null hypothesis of the normal (Gaussian) distribution of random voltage and frequency in the considered power grid is not rejected. 
The agreement between the empirical and theoretical normal distribution is statistically significant. Using the $3 \sigma$ rule, a threshold for these values on the feeder can be determined.

The calculated results for the numerical characteristics of the random variables and Pearson's chi-squared test values are shown in Table 4. The theoretical curves of the Gaussian distribution are plotted in Fig. 2 for voltage and in Fig. 3 for frequency.

\section{ESTIMATION OF THE VOLTAGE AND FREQUENCY VARIATIONS INFLUENCE ON THE RLC-LOAD-CIRCUIT PARAMETERS}

Let us assume that the same voltage and frequency distributions take place in a conventional single-phase power network and find out how the voltage and frequency deviations from their

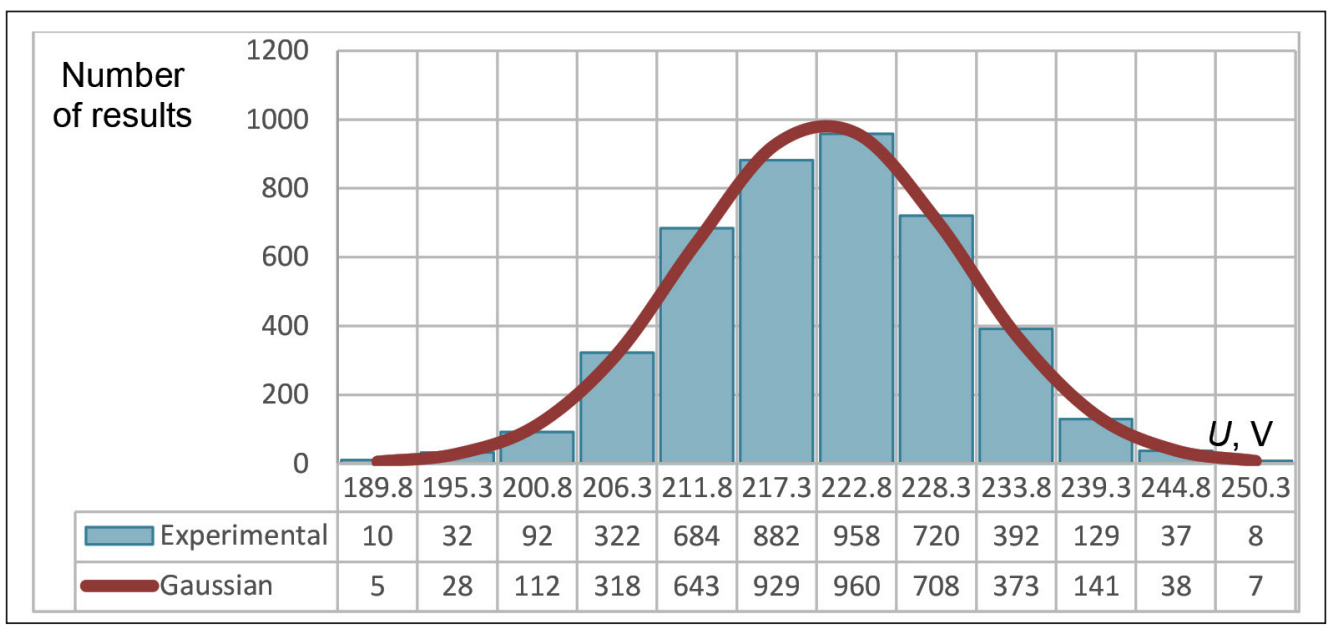

Fig. 2. Probability density function (blue (online) bar chart) and normal distribution (red (online) line) of voltage

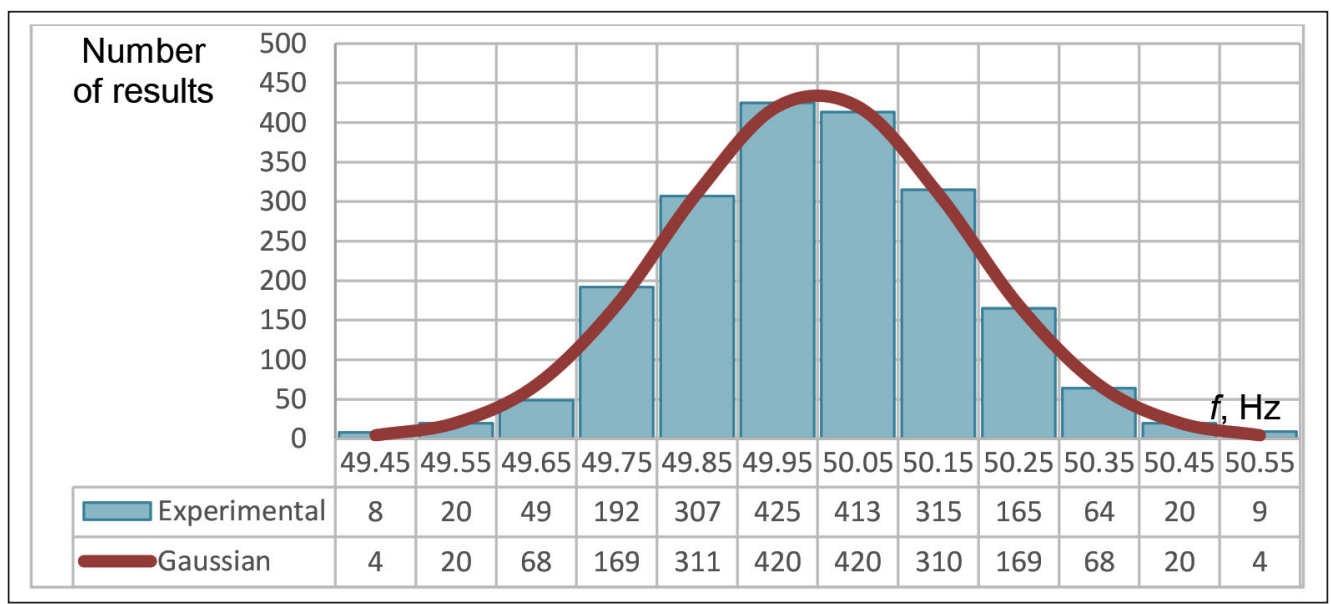

Fig. 3. Probability density function (blue (online) bar chart) and normal distribution (red (online) ine) of frequency

Table 4. Numerical characteristics of the random $U$ and $f$ and the Pearson's chi-squared test values

\begin{tabular}{c|c|c|c|c|c|c|c|c}
\hline $\begin{array}{c}\text { System's } \\
\text { parameter }\end{array}$ & $\boldsymbol{m}_{\boldsymbol{x}^{\prime}}[\mathbf{V}]$ or $[\mathbf{H z}]$ & $\boldsymbol{D}^{*},\left[\mathbf{V}^{\mathbf{2}}\right]$ or $\left[\mathbf{H z}^{2}\right]$ & $\boldsymbol{\sigma}^{*},[\mathbf{V}]$ or $[\mathbf{H z}]$ & $\boldsymbol{I}$ & $\boldsymbol{k}_{\boldsymbol{x}}$ & $\boldsymbol{a}$ & $\boldsymbol{X}_{\exp (X)}^{\mathbf{2}}$ & $\boldsymbol{X}_{\mathrm{cr}(\boldsymbol{X})}^{\mathbf{2}}$ \\
\hline$U$ & 220.52602 & 90.01576 & 9.48766 & 12 & 9 & 0.05 & 16.05771 & 16.91898 \\
$f$ & 49.99982 & 0.03297 & 0.18159 & 12 & 9 & 0.05 & 16.58055 & 16.91898 \\
\hline
\end{tabular}


rated values $(220 \mathrm{~V}$ and $50 \mathrm{~Hz})$ effect the network parameters and the readings of a power meter. Let us consider that an RLC-load, Fig. 4, is connected to such the power network with supply voltage $U=220 \mathrm{~V}$, and the RLC circuit parameters are the following: resistance $R=21.0027 \Omega$, inductance $L=55.42 \mathrm{mH}$, capacitance $C=10^{3} \mu \mathrm{F}$.

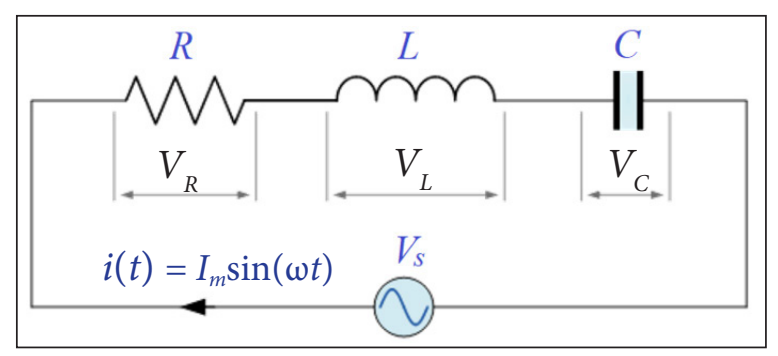

Fig. 4. The series RLC-load-circuit under study

Voltage and frequency variations in the RLC circuit will affect the values of active and reactive power, active and reactive energy, and current. These quantities can be determined by the following formulas:

Active power of the fundamental harmonic

$$
P_{(1)}=U_{(1)} \cdot I_{(1)} \cdot \cos \varphi_{(1)}
$$

where $U_{(1)}$ is the rms voltage value of the fundamental harmonic, $I_{(1)}$ is the rms current value of the fundamental harmonic, and $\cos \varphi_{(1)}$ is the power factor $(\mathrm{PF})$ of the fundamental harmonic.

Reactive power of the fundamental harmonic

$$
Q=U_{(1)} \cdot I_{(1)} \cdot \sin \varphi_{(1)}
$$

Since electric energy consumed in the network is proportional to power $W P \equiv P, W Q \equiv Q$ [12], then the formulas for active and reactive electric energy are

$$
W_{P}=P_{(1)} \cdot t
$$

where $t$ is the time, and

$$
W_{Q}=Q_{(1)} \cdot t .
$$

Here and after it is assumed that the voltage signal does not contain any higher harmonics, subharmonics or interharmonics. If the voltage and current are of a proper sinusoidal waveform, then the readings of electric energy meters will correspond to the formulas $(19,20)$. Hence, this is not the case when harmonic distortions are present in the power network $[13,14]$.

The PF in (17) can be defined as

$$
\cos \varphi=\frac{R}{\sqrt{R^{2}+\left(2 \pi f L-\frac{1}{2 \pi f C}\right)^{2}}},
$$

where $R$ is the resistance, $L$ is the inductance, and $C$ is the capacitance of the electric circuit. The expression $2 \pi f L$ in (20) and (21) corresponds to the inductive circuit reactance $X_{L}[\Omega]$, and the expression $1 / 2 \pi f C$ corresponds to the conductive circuit reactance $X_{C}[\Omega]$. Reactances depend on the values of inductance $L$, capacitance $C$ and frequency in the distributional network $f$.

The value of $\sin \varphi$ in (18) can be defined as

$$
\sin \varphi=\frac{2 \pi f L-\frac{1}{2 \pi f C}}{\sqrt{R^{2}+\left(2 \pi f L-\frac{1}{2 \pi f C}\right)^{2}}} .
$$

The current value is to be determined by the Ohm's law

$$
I=\frac{U}{\sqrt{\left(R^{2}+\left(X_{L}-X_{C}\right)^{2}\right.}} .
$$

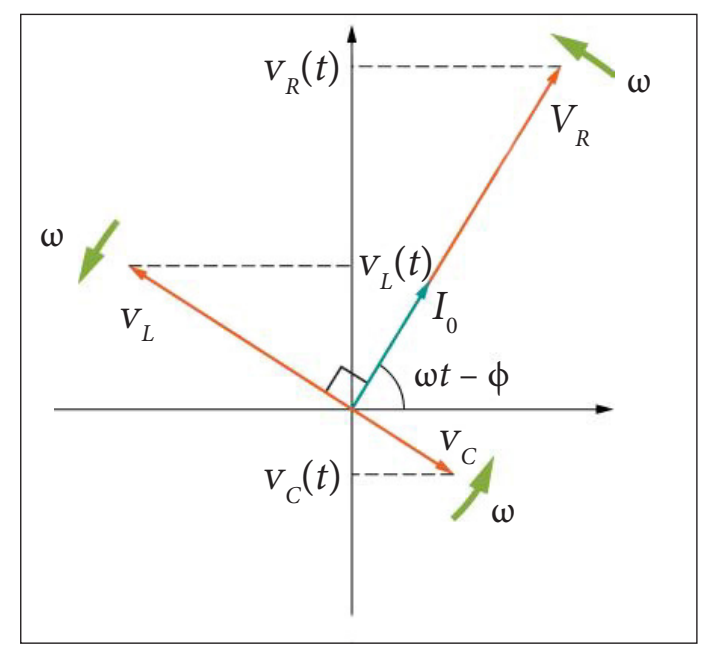

Fig. 5. The principal phasor diagram for the RLC series circuit 
The principal phasor diagram for the RLCload series circuit is shown in Fig. 5. The size of the reactive voltage vector, the $\mathrm{PF}$ and the phase shift between current and voltage depend on the nature of the reactance. The phasor diagram demonstrates the situation when $X_{L}>X_{C}$.

To determine the effect of voltage and frequency variations on the parameters of the electric circuit in Fig. 4, the $\mathrm{C}$ program code was created in Borland $\mathrm{C}++3.1$, according to the methodology given in [15].

\section{Sequence of voltage deviations simulation in \\ Borland C++ 3.1}

1. Consider the cases when the voltage deviates within the following limits regarding $U_{\text {rated }}$ : $\pm 2.5 \%, \pm 5 \%, \pm 7.5 \%, \pm 10 \%, \pm 12.5 \%$ and $\pm 15 \%$.

2. Determine the values of the variance and the standard deviation of voltage by (9)-(13). The mean expectation, variance, standard deviation of voltage and parameters of the electric circuit are entered in the software.

3. For frequency the median $m_{f}=49.9998 \mathrm{~Hz}$ and the standard deviation $\sigma_{f}=0$ are assumed (i.e. the frequency is considered constant). Input these data into the program.

4. The impedance of the electric circuit is considered to be independent from voltage, while reactance is frequency-dependent.

5. The number of calculated iterations to find a random variable: $10^{6}$.
The calculated results are presented in Table 5, and the corresponding dependency graphs are shown in Fig. 6.

It is clear from the graphs of Fig. 6 that voltage variation has a significant effect on active and reactive power, and current in the RLCload. Voltage increase in the electrical network causes an increase in active and reactive power consumption and leads to higher current flows, while voltage decrease has a reverse effect on the named values. According to (19) and (20), voltage variations have a similar effect on the readings of active and reactive power meters, under the assumption that voltage deviations in the ranges specified in Table 5 do not affect

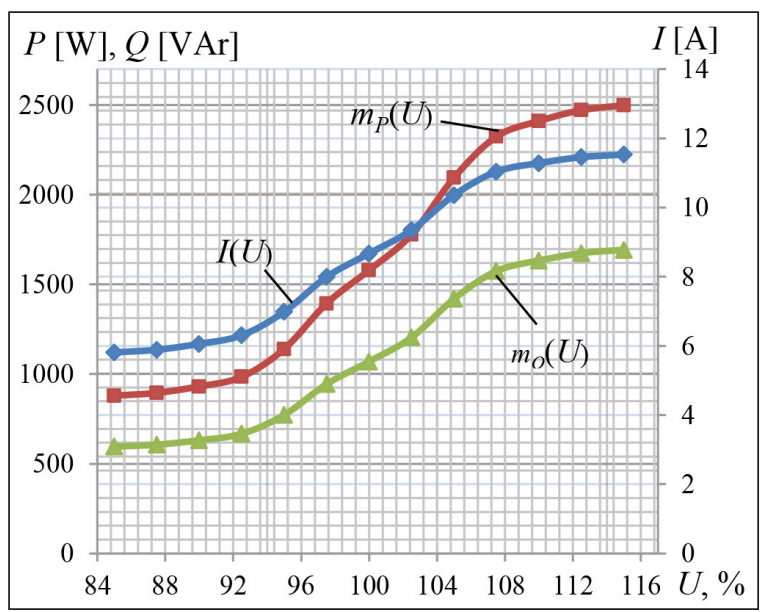

Fig. 6. Dependency graphs for $m_{p}(U), m_{Q}(U)$ and $I_{m}(U)$

Table 5. The results of voltage variation simulation

\begin{tabular}{|c|c|c|c|c|c|c|c|c|c|c|c|}
\hline \multicolumn{3}{|c|}{ Calculation results } & \multicolumn{9}{|c|}{ Results of simulation } \\
\hline $\begin{array}{c}\boldsymbol{U}_{\text {rated" }} \\
\%\end{array}$ & $\begin{array}{l}D_{U^{\prime}} \\
V^{2}\end{array}$ & $\begin{array}{c}\sigma_{u^{\prime}} \\
V\end{array}$ & $\cos \varphi$ & $\sin \varphi$ & $\begin{array}{l}\text { I, } \\
\text { A }\end{array}$ & $\begin{array}{c}X_{L^{\prime}} \\
\Omega\end{array}$ & $\begin{array}{c}X_{c^{\prime}} \\
\Omega\end{array}$ & $\begin{array}{c}m_{p^{\prime}} \\
W\end{array}$ & $\begin{array}{l}\sigma_{p^{\prime}} \\
W\end{array}$ & $\begin{array}{l}m_{Q^{\prime}} \\
\text { VAr }\end{array}$ & $\begin{array}{c}\sigma_{Q^{\prime}} \\
\text { VAr }\end{array}$ \\
\hline 85 & 88.43176 & 9.4038 & 0.827919 & 0.560847 & .81233 & 17.4107 & 3.1831 & 879.413 & 141.853 & 595.73 & 96.094 \\
\hline 87.5 & 83.82168 & 9.1554 & 0.827919 & 0.560847 & 5.88788 & 17.4107 & 3.1831 & 895.092 & 139.344 & 606.352 & 95.3944 \\
\hline 90 & 73.81909 & 8.5918 & 0.827919 & 0.560847 & 6.05928 & 17.4107 & 3.1831 & 931.235 & 133.404 & 630.835 & 90.3704 \\
\hline 92.5 & 51496 & 91 & 17 & 0 & 5 & 07 & 31 & 36 & 33 & 78 & 78 \\
\hline 95 & 30.7723 & 5473 & 19 & 0847 & 6.98521 & 107 & 3.1831 & 1140.07 & 574 & 2.305 & 64.5968 \\
\hline 97.5 & 4.971675 & 2.2297 & 0.827919 & 0.560847 & 7.9942 & 17.4107 & 3.1831 & 1393.77 & 42.3842 & 944.168 & 28.7118 \\
\hline 100 & 0 & 0 & 0.827919 & 0.560847 & 8.67232 & 17.4107 & 3.1831 & 1579.6 & 0.000688 & 1070.05 & 0.000594 \\
\hline 102.5 & 4.971675 & 2.2297 & 0.827919 & 0.560847 & 9.35045 & 17.4107 & 3.1831 & 1777.73 & 47.8545 & 1204.27 & 32.4175 \\
\hline 105 & 7723 & 473 & 827919 & 0. & .3594 & .4107 & 331 & 20 & 08 & 1419.41 & 87.5277 \\
\hline 107.5 & 60.51496 & 791 & 0.827919 & 0847 & 11.0382 & 17.4107 & 3.1831 & 2324.3 & 190.779 & 1574.52 & 129.237 \\
\hline 110 & 73.81909 & 8.5918 & 0.827919 & 0.560847 & 11.2854 & 17.4107 & 3.1831 & 2410.75 & 214.569 & 1633.08 & 145.353 \\
\hline 112.5 & 83.82168 & 9.1554 & 0.827919 & 0.560847 & 11.4568 & 17.4107 & 3.1831 & 2471.66 & 231.496 & 1674.34 & 156.82 \\
\hline 115 & 88.43176 & 9.4038 & 0.827919 & 0.560847 & 11.5323 & 17.4107 & 3.1831 & 2498.75 & 239.069 & 1692.7 & 161.949 \\
\hline
\end{tabular}


the accuracy of active and reactive electric energy determination by the meter. For the considered case, if the voltage is $+15 \%$ of $U_{\text {rated }}$ then electric energy consumption (for both active $W_{P}$ and reactive $W_{Q}$ component) will be $158.19 \%$ higher than for $220 \mathrm{~V}$ supply voltage. If the voltage is $-15 \%$ of its rated value, then electric energy consumption will be just $55.67 \%$ of the electric energy consumption of the $220 \mathrm{~V}$ supply voltage. Even small voltage variations lead to significant changes of power flow. Therefore, to optimize power consumption, power losses and equipment lifespan, voltage is desired to be as close to its rated value as possible.

\section{Sequence of frequency deviations simulation} in Borland $\mathrm{C}++3.1$

1. Consider the cases when the frequency deviates within the following limits regarding $f_{\text {rated }} \pm 0.2 \%$, $\pm 0.4 \%, \pm 0.6 \%, \pm 0.8 \%, \pm 1 \%$ and $\pm 1.2 \%$.

2. Determine the values of the variance and the standard deviation of frequency by (9)-(13). The mean expectation, variance, standard deviation of frequency and parameters of the electric circuit are entered in the software.

3. For voltage the median $m_{U}=219.98 \mathrm{~V}$ and the standard deviation $\sigma_{U}=0$ are assumed (i.e. voltage is considered constant). Input these data into the program.

4. The impedance of the electric circuit is considered to be independent from voltage, while reactance is frequency-dependent.
5. The number of calculated iterations to find a random variable: $10^{6}$.

The obtained results are summarized in Table 6 , and the corresponding dependency graphs are shown in Figs. 7 and 8.

As seen from the graphs of Figs. 7 and 8, the influence of frequency variations within the considered limits on the values of active and reactive power and other parameters of the RLC-circuit are insignificant. The slope of the graphs is very smooth and barely noticeable. Frequency increase/decrease causes very small changesinactiveandreactive powerconsumption.

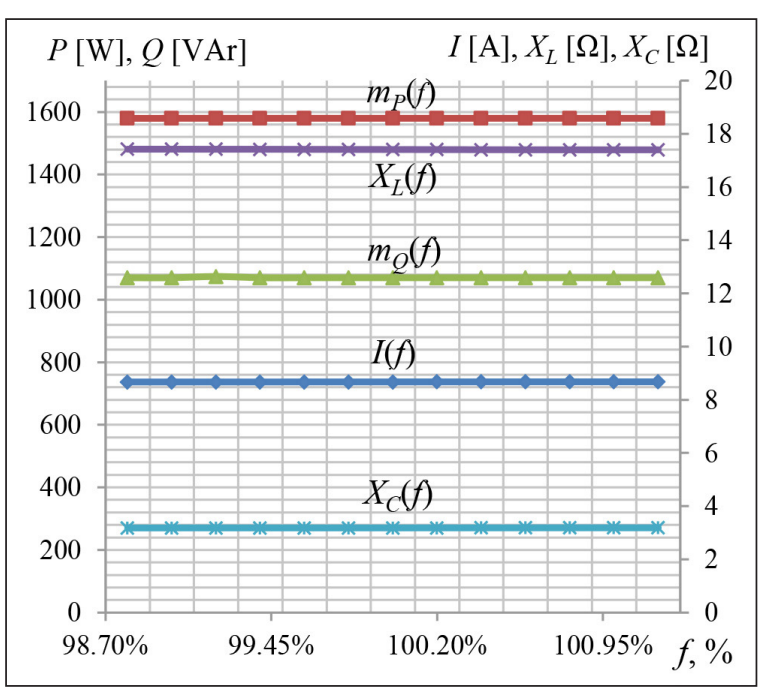

Fig. 7. Dependency graphs for $m_{p}(f), m_{Q}(f), I(f), X_{L}(f)$ and $X_{C}(f)$

Table 6 . The results of frequency variation simulation

\begin{tabular}{|c|c|c|c|c|c|c|c|c|c|c|c|}
\hline \multicolumn{3}{|c|}{ Calculation results } & \multicolumn{9}{|c|}{ Results of simulation } \\
\hline $\begin{array}{c}\boldsymbol{f}_{\text {ratedı }} \\
\%\end{array}$ & $\begin{array}{l}D_{f^{\prime}} \\
H z^{2}\end{array}$ & $\begin{array}{l}\sigma_{f^{\prime}} \\
\mathrm{Hz}\end{array}$ & $\cos \varphi$ & $\sin \varphi$ & I, & $\begin{array}{c}X_{L^{\prime}} \\
\Omega\end{array}$ & $\begin{array}{c}X_{C^{\prime}} \\
\Omega\end{array}$ & $\begin{array}{c}m_{p^{\prime}} \\
\mathbf{W}\end{array}$ & $\begin{array}{l}\sigma_{p^{\prime}} \\
W\end{array}$ & $\begin{array}{l}m_{Q^{\prime}} \\
\text { VAr }\end{array}$ & $\begin{array}{l}\sigma_{Q^{\prime}} \\
\text { VAr }\end{array}$ \\
\hline 98.8 & 0.033656437 & 0.18346 & 0.827673 & 0.561211 & 8.66975 & 17.4221 & 3.18102 & 1579.58 & 5.29893 & 1070.04 & 2.11628 \\
\hline 99 & 0.031759011 & 0.17821 & 0.82768 & 0.5612 & 8.66982 & 17.4218 & 3.18108 & 1579.59 & 5.1473 & 1070.04 & 2.05571 \\
\hline 99.2 & 0.028191967 & 0.16790 & 0.827694 & 0.56118 & 8.66996 & 17.4211 & 3.1812 & 1579.59 & 4.849952 & 1074.04 & 1.93677 \\
\hline 99.4 & 0.022126468 & 0.14875 & 0.82772 & 0.561142 & 8.67023 & 17.4199 & 3.18141 & 1579.59 & 4.29643 & 1070.04 & 1.71587 \\
\hline 99.6 & 0.009665499 & 0.09831 & 0.827787 & 0.561042 & 8.67094 & 17.4168 & 3.18199 & 1579.59 & 2.83958 & 1070.05 & 1.13403 \\
\hline 99.8 & 0.001507312 & 0.03882 & 0.827867 & 0.560924 & 8.67178 & 17.4131 & 3.18266 & 1579.59 & 1.12129 & 1070.05 & 0.447814 \\
\hline 100 & 0 & 0 & 0.827919 & 0.560847 & 8.67232 & 17.4107 & 3.1831 & 1579.6 & 0.000688 & 1070.05 & 0.000594 \\
\hline 100.2 & 0.001507312 & 0.03882 & 0.827971 & 0.56077 & 8.67287 & 17.4083 & 3.18354 & 1579.6 & 1.1213 & 1070.04 & 0.447855 \\
\hline 100.4 & 0.009665499 & 0.09831 & 0.828051 & 0.560653 & 8.67371 & 17.4046 & 3.18421 & 1579.61 & 2.83967 & 1070.04 & 1.13429 \\
\hline 100.6 & 0.022126468 & 0.14875 & 0.828119 & 0.560553 & 8.67442 & 17.4015 & 3.18479 & 1579.61 & 4.29665 & 1070.03 & 1.71646 \\
\hline 100.8 & 0.028191967 & 0.16790 & 0.828145 & 0.560515 & 8.67468 & 17.4003 & 3.185 & 1579.62 & 4.82981 & 1070.03 & 1.93754 \\
\hline 101 & 0.031759011 & 0.17821 & 0.828158 & 0.560494 & 8.67483 & 17.3997 & 3.18512 & 1579.62 & 5.14762 & 1070.02 & 2.05657 \\
\hline 101.2 & 0.033656437 & 0.18346 & 0.828165 & 0.560484 & 8.6749 & 17.3993 & 3.18518 & 1579.62 & 5.29927 & 1070.02 & 2.11719 \\
\hline
\end{tabular}




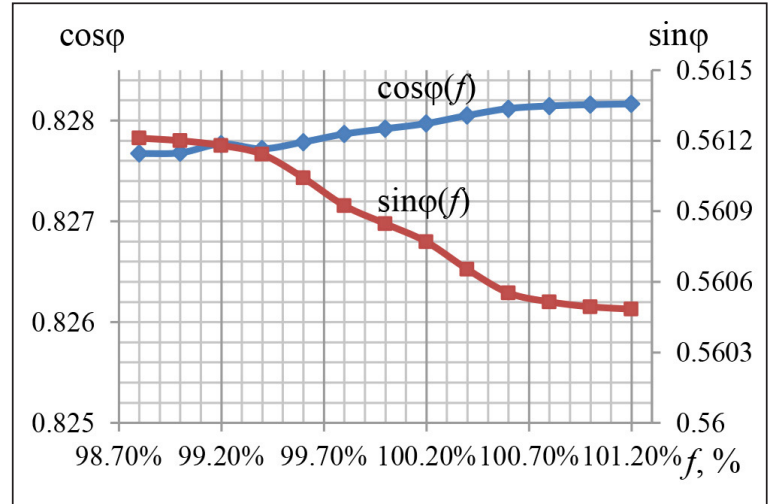

Fig. 8. Dependency graphs for $\cos \varphi(f)$ and $\sin \varphi(f)$

According to formulas (19) and (20), frequency variations within the considered range will hardly change the readings of active and reactive power meters. For the considered example, if the frequency is $+1.2 \%$ of $f_{\text {rated }}$ then electric energy will be just $100.0013 \%$ higher for $W_{P}$, and $99.9972 \%$ lower for $W_{Q}$, compared to the case when the frequency is $50 \mathrm{~Hz}$. If the frequency is $-1.2 \%$ of its rated value, then electric energy consumption will be just $99.9987 \%$ lower for $W_{P}$, and $99.9991 \%$ lower for $W_{Q}$, compared to the case when the frequency is $50 \mathrm{~Hz}$.

\section{DOES VOLTAGE ALWAYS OBEY THE GAUSSIAN DISTRIBUTION?}

Although under normal operating conditions the voltage variations at the customer's side are considered to be of a stochastic character and can be described by a normal distribution [3], this may not be the rule for all consumers and for all points in the LV/MV distribution power grid. For the example discussed in the previous sections, the null hypothesizes of Gaussian distribution of voltage and frequency were validated and accepted. However, the distribution laws of these quantities in the LV or MV power networks may be different, e.g. hypergeometric, binominal, negative binomial, log-normal, chi-squared, Poisson, Student's, Cauchy, Weibull, gamma or other.

To check this statement, five series of measurements of the voltage profile were taken at the university facility. The measurements were taken for three workdays (Monday, Wednesday, Friday) and for weekend. 18000 voltage measurements were made for each sample at $1 \mathrm{~s}$ step, using a power quality analyzer ENA330, Class A (Czech Republic). The data were processed according to the above described method, using the numerical characteristics of the random variables and their systems, and the Pearson's chi-squared test was made to verify whether the voltage profiles obey the normal distribution law. The results of the calculations are summarized in Table 7. The $f(U)$ dependences are demonstrated in Fig. 9.

For all the five cases, the Pearson's chi-squared test condition $\chi_{\exp (x)}^{2}<\chi_{\operatorname{ecr}(x)}^{2}$ is not satisfied, which means that the null hypothesis of the normal distribution of random voltage at the university's grid should be rejected. In other words, the assumed normal distribution poorly describes the empirical data. Fig. 9(a-e) also reveals noticeable disparities between the theoretical Gaussian curve and the graphs plotted from the experimental results.

\section{CONCLUSIONS}

Power quality is characterized by the voltage quality and the frequency quality of AC voltage. In this paper, the undesired impacts of voltage and frequency variations and control strategies to maintain these PQ indicators at the appropriate levels are analysed. Requirements of

Table 7. Numerical characteristics of the random $U$ and the Pearson's chi-squared test results

\begin{tabular}{c|c|c|c|c|c}
\hline Sample No. & $\boldsymbol{m}_{\boldsymbol{U}_{\boldsymbol{\prime}}}[\mathbf{V}]$ & $\boldsymbol{D}_{U_{\boldsymbol{\prime}}}^{*}\left[\mathbf{V}^{2}\right]$ & $\boldsymbol{\sigma}_{U_{,}}^{*}[\mathbf{V}]$ & $\boldsymbol{X}_{\exp (\boldsymbol{U})}^{2}$ & $\boldsymbol{X}_{\operatorname{ecr}(\boldsymbol{U})}^{2}$ \\
\hline 1 & 226.62891 & 0.31456 & 0.56086 & 413.95754 & 21.02607 \\
\hline 2 & 228.79213 & 0.7718 & 0.87852 & 4352.56972 & 21.02607 \\
\hline 3 & 228.73425 & 0.16745 & 0.40921 & 1659.83991 & 21.02607 \\
\hline 4 & 227.38246 & 0.53085 & 0.72859 & 1796.04649 & 21.02607 \\
\hline 5 & 229.56258 & 0.14817 & 0.38493 & 1177.21162 & 21.02607 \\
\hline
\end{tabular}



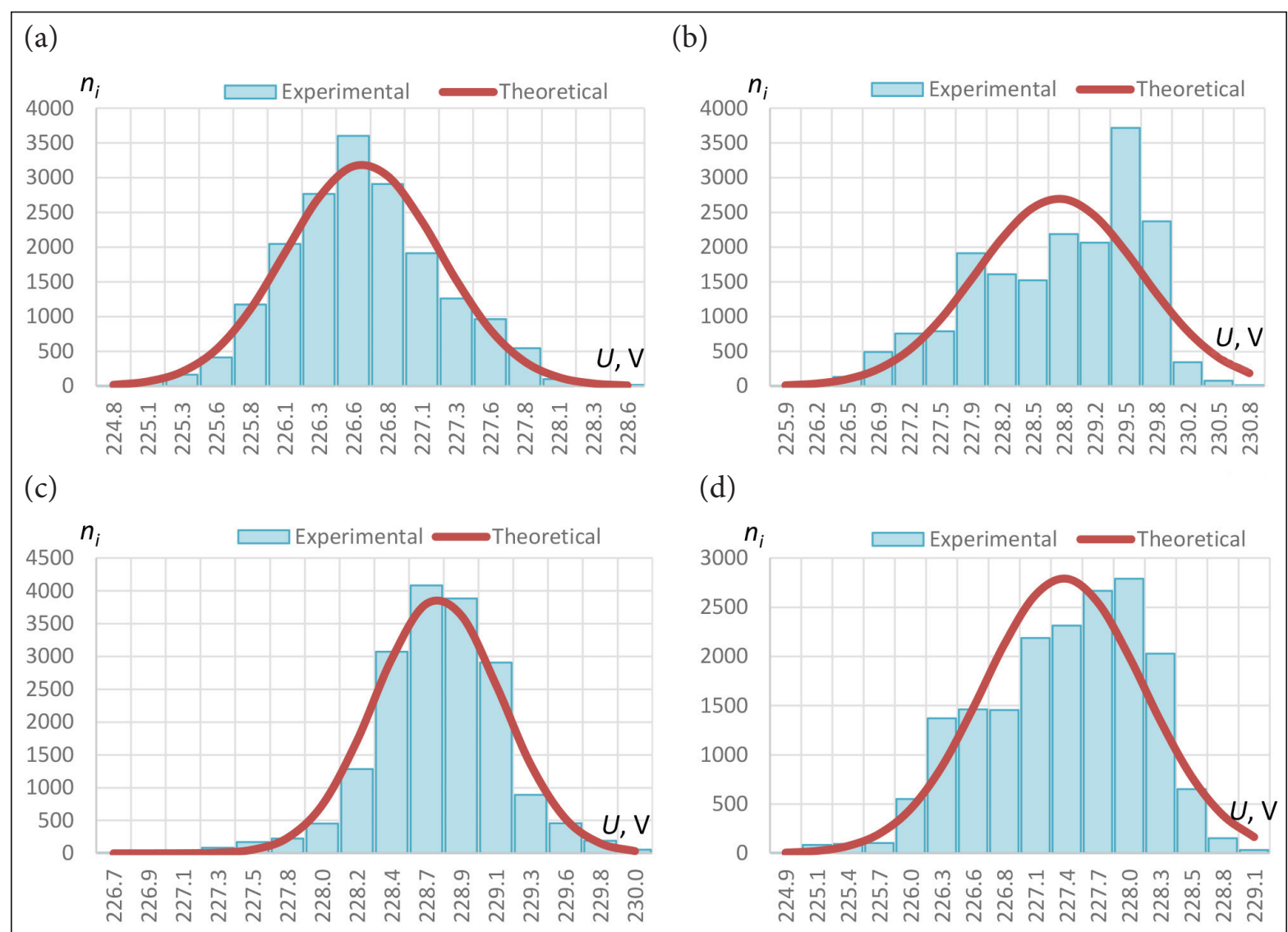

(d)

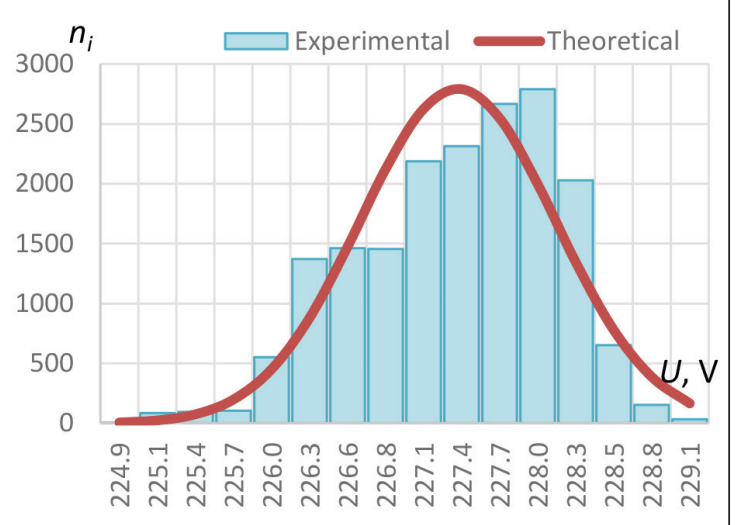

(e)

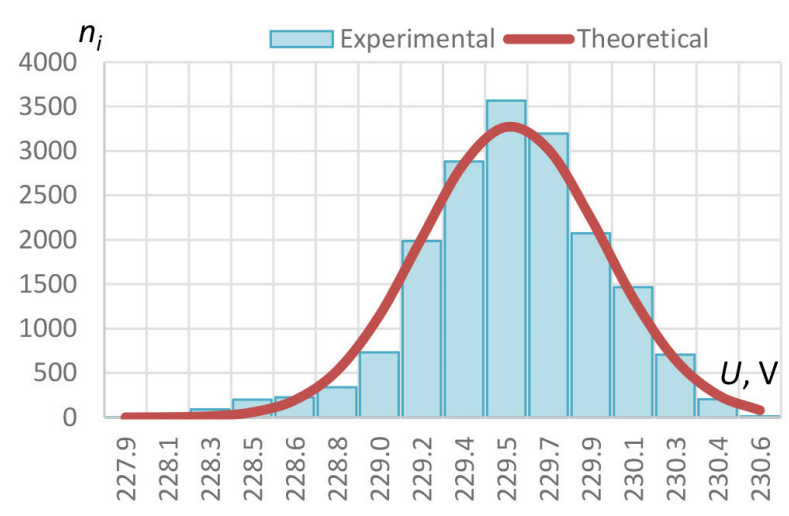

Fig. 9. Probability density function (blue (online) bar chart) and normal distribution (red (online) line) of voltage for (a) workday (Monday), (b) workday (Wednesday), (c) workday (Friday), (d) weekend (Saturday) and (e) weekend (Sunday)

the EN 50160 standard for PQ regulation, valid in Ukraine and the EU, are also considered. The results of voltage and frequency measurements were processed using the numerical characteristics of random variables and their systems, and the hypothesizes of Gaussian distribution of voltage and frequency were validated and accepted. Assuming that similar voltage and frequency profiles take place in a single-phase LV distribution network, it was evaluated how their deviations from the rated values $(220 \mathrm{~V}$ and $50 \mathrm{~Hz})$ effect the network parameters and the readings of a power meter. The load was represented as a series RLC-circuit.

Voltage profile is of great importance to consumers because it is a basic demand for electrical equipment running near the rated voltage. Even small voltage variations significantly change the power flow. For the considered case, if 
the voltage is $+15 \%$ of $U_{\text {rated }}$, then electric energy consumption, for both $W_{P}$ and $W_{Q}$ components, will be 1.6 times higher, compared to the case when the supply voltage rms value is $220 \mathrm{~V}$. If the voltage is $-15 \%$ of its rated value, then electric energy consumption will be 1.8 times lower, compared to the $220 \mathrm{~V}$ case. Thus, to optimize power consumption, power losses and equipment lifespan, it is desirable to maintain voltage as close to its rated value as possible. For the considered case study, frequency deviations within the range $\pm 1.2 \%$ of $f_{\text {rated }}$ demonstrated a negligible influence on the RLC-load-circuit parameters and the theoretical readings of active and reactive power meters. Although the frequency variation seems to be not critical, it is important to maintain its value within the acceptable limits, since the frequency deviations worsen the operation of asynchronous motors and other equipment. Thus, the limits given in EN 50160-2010 should be respected.

Under normal operating conditions, the voltage variations at the customer's side have a stochastic nature. For some cases, the voltage profile obeys the normal distribution. However, distribution of the random variable (voltage) depends on the type of load and the point of measurement in the LV and MV distribution power systems, which means that its distribution law should be defined for each case separately.

Received 5 August 2019 Accepted 5 December 2019

\section{References}

1. Almeida A. B. et al. Probabilistic voltage stability assessment considering renewable sources with the help of the PV and QV curves. IET Renewable Power Generation. 2013. Vol. 7. No. 5. P. 521-530.

2. Gerasimenko A. A., Fedin V. T. Peredacha $i$ raspredelenie elektricheskoj energii (Electric Energy Transmission and Distribution). Krasnoyarsk: Izdatelskie proekty, 2006.

3. Vinnal T., Janson K., Järvik J., Kalda H., Sakkos T. Supply voltage quality in low voltage industrial networks of Estonia. Estonian Journal of Engineering. 2012. Vol. 18. No. 2. P. 102-126.

4. Chen P. C. et al. Analysis of voltage profile problems due to the penetration of distributed gen- eration in low-voltage secondary distribution networks. IEEE Transactions on Power Delivery. 2012. Vol. 27. No. 4. P. 2020-2028.

5. Tonkoski R., Turcotte D., El-Fouly T. H. M. Impact of high PV penetration on voltage profiles in residential neighborhoods. IEEE Transactions on Sustainable Energy. 2012. Vol. 3. No. 3. P. 518-527.

6. Volokhin V. V., Diahovchenko I. M., Derevyanko B. V. Electric energy accounting and power quality in electric networks with photovoltaic power stations. Proceedings of 2017 IEEE International Young Scientists Forum on Applied Physics and Engineering, YSF 2017, 2017, Lviv, Ukraine. P. 36-39.

7. Shevchenko S. Y., Volokhin V. V., Diahovchenko I. M. Power quality issues in smart grids with photovoltaic power stations. Energetika. 2017. Vol. 63. No. 4. P. 146-153.

8. Electrical Distribution System Protection. Cooper Power Systems, 2005.

9. McPherson G. Applying and Interpreting Statistics, A Comprehensive Guide. 2nd ed. New York: Springer-Verlag, 2001.

10. Pearson K. X. On the criterion that a given system of deviations from the probable in the case of a correlated system of variables is such that it can be reasonably supposed to have arisen from random sampling. London, Edinburgh, and Dublin Philosophical Magazine and Journal of Science. 1900. Vol. 50. No. 302. P. 157-175.

11. Sturges H. A. The choice of a class interval. Journal of the American Statistical Association. 1926. Vol. 21. No. 153. P. 65-66.

12. Volokhin V., Diahovchenko I., Kurochkina V., Kanálik M. The influence of nonsinusoidal supply voltage on the amount of power consumption and electricity meter readings. Energetika. 2017. Vol. 63. No. 1. P. 1-7.

13. Diahovchenko I., Volokhin V., Kurochkina V., Špes M., Kosterec M. Effect of harmonic distortion on electric energy meters of different metrological principles. Frontiers in Energy. 2019. Vol. 13. No. 2. P. 377-385.

14. Morva G., Volokhin V., Diahovchenko I., Čon$\mathrm{ka} Z$. Analysis of the impact of nonlinear distortion in voltage and current curves on the errors of electric energy metering devices. Proceedings of 2017 IEEE 1st Ukraine Conference on Electrical 
and Computer Engineering, UKRCON 2017, 2017, Kiev, Ukraine. P. 528-533.

15. Shevchenko S. Yu. et al. Doslidzhennia vplyvu vidkhylennia elektrychnoi napruhy ta chastoty na pokazy pryladiv obliku elektrychnoi enerhii (Investigation of the effect of voltage and frequency deviation on the readings of electricity meters). Vistnyk NTU “HPI”. 2015. P. 119-125.

16. EN 50160: 2010, Voltage characteristics of electricity supplied by public electricity networks.
Illia Diahovchenko, Nataliia Sushchenko, Anton Shulumei, Oleksandr Strokin

\section{MAITINIMO İTAMPOS IR DAŽNIO VARIACIJOS ITTAKA ELEKTROS İRANGAI BEI ŽEMOS IR VIDUTINĖS İTAMPOS TINKLŲ APKROVOMS}

\section{Santrauka}

Straipsnyje analizuojama maitinimo įtampa ir dažnio kokybė žemos ir vidutinès įtampų skirstomuosiuose tinkluose. İtampos ir dažnio variacijų, galiojančių nepažeidžiant nustatytų standartų ribų, ịtaka elektros tinklo parametrams buvo ištirta remiantis tikimybių teorija ir statistika. Ivertinimui naudota RLC tipo grandinè su apkrova. Buvo sudarytas įtampos ir dažnio variacijų skirstinys ir pasiūlytos optimalios ịtampos ir dažnio kokybès parametrų vertès, atsižvelgiant $i$ energijos naudojimą, tinklo nuostolius ir elektros ịrangos gyvavimo laiką.

Raktažodžiai: įtampos variacijos, dažnio variacijos, energijos kokybè, elektros energijos skaitiklis, normalusis skirstinys, Pirsono (Chi kvadratu) kriterijus, elektros skirstomasis tinklas 